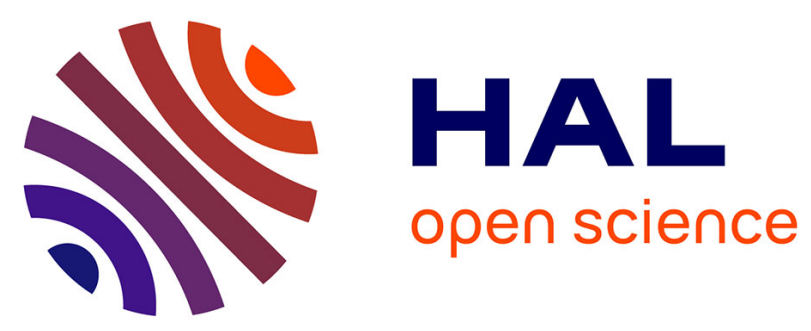

\title{
Mixed valence trimers in cation radical salts of TMTTF with the planar bis(6-sulfo-8-quinolato) platinum complex $[\operatorname{Pt}(\mathrm{qS})(2)](2-)$
}

Arkadiusz Fracckowiak, Boleslaw Barszcz, Iwona Olejniczak, Mikolaj Tomasik, Natalia Jarzyniak, Roman Swietlik, Pascale Auban-Senzier, Marc Fourmigué,

Olivier Jeannin, Franck Camerel

\section{To cite this version:}

Arkadiusz Frąckowiak, Boleslaw Barszcz, Iwona Olejniczak, Mikolaj Tomasik, Natalia Jarzyniak, et al.. Mixed valence trimers in cation radical salts of TMTTF with the planar bis(6-sulfo-8quinolato) platinum complex $[\mathrm{Pt}(\mathrm{qS})(2)](2-)$. New Journal of Chemistry, 2020, 44 (36), pp.1553815548. 10.1039/d0nj03584j . hal-02996253

\section{HAL Id: hal-02996253 \\ https://hal.science/hal-02996253}

Submitted on 17 Nov 2020

HAL is a multi-disciplinary open access archive for the deposit and dissemination of scientific research documents, whether they are published or not. The documents may come from teaching and research institutions in France or abroad, or from public or private research centers.
L'archive ouverte pluridisciplinaire HAL, est destinée au dépôt et à la diffusion de documents scientifiques de niveau recherche, publiés ou non, émanant des établissements d'enseignement et de recherche français ou étrangers, des laboratoires publics ou privés. 


\title{
Mixed valence trimers in cation radical salts of TMTTF with the planar bis(6-sulfo-8-quinolato) platinum complex $\left[\mathrm{Pt}(\mathrm{qS})_{2}\right]^{2-}$
}

\author{
Arkadiusz Frąckowiak, ${ }^{\text {a,c }}$ Bolesław Barszcz, ${ }^{a}$ Iwona Olejniczak, ${ }^{a}$ Mikołaj Tomasik ${ }^{a}$, Natalia Jarzyniak ${ }^{a}$, Roman Świetlik, ${ }^{*}{ }^{a}$ \\ Pascale Auban-Senzier, ${ }^{\mathrm{b}}$ Marc Fourmigué, ${ }^{c}$ Olivier Jeannin, ${ }^{c}$ and Franck Camerel*,c
}

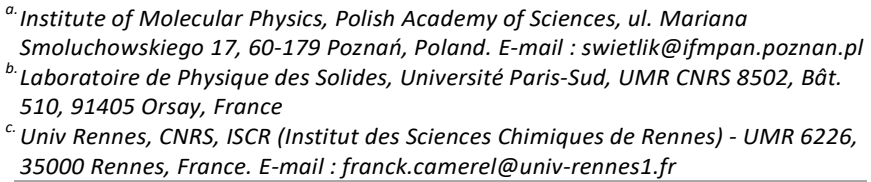

Electrocrystallization of TMTTF (tetramethyltetrathiafulvalene) in the presence of the dianionic [Pt(qS) $]^{2-}$ platinum complex (qS: 5 -sulfo-8-quinolinol) afforded simultaneously two phases. Phase A with isolated dicationic (TMTTF) ${ }_{2}{ }^{2+}$ species is fully insulating and characterized by $\mathrm{C}-\mathrm{H}$ hydrogen bonds with the anionic sulfonate moieties. Phase $B$ is a mixed valence salt formulated as (TMTTF $)_{3}\left[\mathrm{Pt}(\mathrm{qS})_{2}\right]$. It is organized into strongly trimerized chains, with a notably higher conductivity $\left(\sigma_{R T}=4 \times 10^{-5} \mathrm{Scm}^{-1}\right)$. Charge distribution within the TMTTF trimers has been evaluated from the intramolecular bond distances, and IR and Raman spectra, converging all to a $+0.5 /+1 /+0.5$ motif, which is not modified at lower temperatures. Spectroscopic studies of such trimeric structures are scarce and the doublet (or triplet) structure expected in the IR of trimers is clearly identified here in the EMV-activated $v_{8}\left(\mathrm{a}_{\mathrm{g}}\right.$ ) mode associated with the totally symmetric vibration of methyl groups, in relation with the weak $\mathrm{C}-\mathrm{H} \bullet \bullet \bullet \mathrm{O}$ hydrogen bonds between radical cation and the dianionic $\left[\mathrm{Pt}(\mathrm{qS})_{2}\right]^{2-}$ platinum complex.

\section{Introduction}

Most molecular conductors based on cation radical salts are built from the association in the crystal of partially oxidized tetrathiafulvalene (TTF) derivatives (TMTTF, TMTSF, BEDT-TTF, ...) and small inorganic counter ions such as $\mathrm{Br}^{-}, \mathrm{PF}_{6}^{-}, \mathrm{I}_{3}^{-}, \ldots$ or more complex metallate anions such as $\mathrm{AuI}_{2}^{-}, \mathrm{Cu}(\mathrm{NCS})_{2}{ }^{-}$or $\mathrm{Cu}\left[\mathrm{N}(\mathrm{CN})_{2}\right] \mathrm{Br}^{-} \ldots$ Besides such inorganic counter ions, organic anions such as carboxylates or sulfonates have been also successfully investigated in conducting cation radical salts with TTF derivatives. ${ }^{1}$ One can mention aliphatic sulfonates such as $\mathrm{F}_{3} \mathrm{C}-\mathrm{SO}_{3}$ $, 2,3$ or $\mathrm{F}_{5} \mathrm{SCH}_{2} \mathrm{CF}_{2} \mathrm{SO}_{3}^{-},{ }_{1,4}$ aromatic sulfonates $\left(\mathrm{C}_{6} \mathrm{~F}_{5}-\mathrm{SO}_{3}^{-}, \mathrm{C}_{6} \mathrm{H}_{5-}\right.$ $\mathrm{CH}_{2}-\mathrm{SO}_{3}^{-5}, \mathrm{HO}_{2} \mathrm{C}-p-\mathrm{C}_{6} \mathrm{H}_{4}-\mathrm{SO}_{3}^{-6}, \quad N, N$-disulfo-1,4-benzoquinonediimine, $^{7} \quad 1,1^{\prime}$-ferrocene-disulfonate), ${ }^{8}$ or sulfonate anions substituted with aminoxyl radical species. ${ }^{9-26}$ Aromatic disulfonate salts (Scheme 1) were also used for that purpose, involving 1,5naphtalenedisulfonate, ${ }^{5}$ 2,6-naphthalene- and 2,6-anthracenedisulfonate (Scheme 1). ${ }^{27}$

One interesting peculiarity of these conducting TTF salts with sulfonate anions is the recurrent presence of $\mathrm{C}-\mathrm{H} \cdots \mathrm{O}_{3} \mathrm{~S}$ hydrogen bond interactions between the TTF hydrogen atoms (activated upon TTF oxidation) ${ }^{28}$ and the negatively charged oxygen atoms of the

† Electronic Supplementary Information (ESI) available: [details of any supplementary information available should be included here]. See DOI: $10.1039 / x 0 x x 00000 x$ sulfonate moiety. Such hydrogen bonds involving carbon-bonded hydrogen atoms, albeit weak, have been shown to play a crucial role in the organic solid state, ${ }^{29}$ and particularly in molecular conductors. 28, 30-32 We have for example shown that the BEDT-TTF salt with 2,6-anthracene-bis(sulfonate) exhibits a metal-insulator transition at $T_{M I}=85 \mathrm{~K}$ which finds its origin in minute modifications of such C$\mathrm{H} \cdots \mathrm{O}$ interactions, leading to a charge ordering process and gap opening. ${ }^{27}$ Sulfonate anions can also act as halogen bond (rather than hydrogen bond) acceptors and cation radical salts with iodinated tetrathiafulvalenes were also reported, exhibiting strong $\mathrm{C}_{\mathrm{TTF}}-\mathrm{I} \cdot \cdots \mathrm{O}_{3} \mathrm{~S}-\mathrm{R}$ halogen bonds. ${ }^{33,34}$

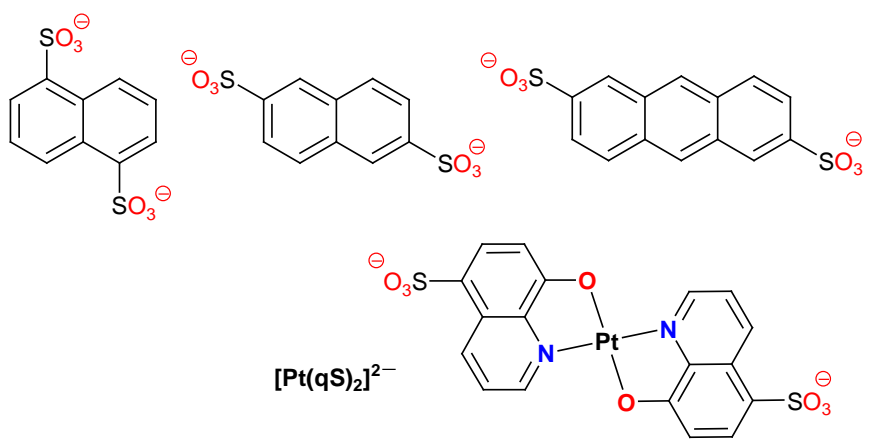

Scheme 1. Aromatic disulfonate derivatives used as counter ions in conducting salts.

In the course of our investigations of such complex sulfonate anions, ${ }^{35-39}$ we developed recently a platinum(II) chelate of 5-sulfo8-quinolinol, $\left[\mathrm{Pt}(\mathrm{qS})_{2}\right]^{2-}$, which can be associated through the socalled ionic self-assembly (ISA) approach, with various ammonium cations such as $\left(\mathrm{H}_{2 \mathrm{n}+1} \mathrm{C}_{\mathrm{n}}\right)_{2} \mathrm{Me}_{2} \mathrm{~N}^{+}(\mathrm{n}=12,16,18)$ to afford phosphorescent crystalline or liquid crystalline phases. ${ }^{40}$ Its availability prompted us to use this planar bis-sulfonate as counter ion in cation radical salts with TTF derivatives. We describe here 
two phases we obtained concomitantly in the presence of TMTTF, with different degrees of charge transfer, as demonstrated here from combined structural and spectroscopic (IR, Raman) investigations.

\section{Experimental}

Materials. The phosphonium salt, $\left[\mathrm{PPh}_{4}\right]_{2}\left[\left[\mathrm{Pt}(\mathrm{qS})_{2}\right]\right.$ as well as the potassium and the sodium derivatives were prepared as previously reported. ${ }^{27}$ TMTTF was prepared as previously described. ${ }^{41} 1,1,2-$ trichloroethane (TCE) was purchased form TCI Europe and used as received.

Electrocrystallization. Two-compartment electro-crystallization cells, equipped with Pt wires (diameter $1 \mathrm{~mm}$, length $2 \mathrm{~cm}$ ), were filled with TMTTF (10 mg) in the anodic compartment and a solution of $\left[\mathrm{PPh}_{4}\right]_{2}\left[\left[\mathrm{Pt}(\mathrm{qS})_{2}\right](50 \mathrm{mg})\right.$ in 1,1,2-trichloroethane $(5 \mathrm{~mL}$ $+25 \mu \mathrm{L} \mathrm{H}_{2} \mathrm{O}$ ) as electrolyte in both compartments. Water was added to improve the solubility of the sulfonate derivative. Electrocrystallizations were performed at $20{ }^{\circ} \mathrm{C}$ with a constant current of $0.5 \mu$ A during 11 days. (TMTTF) $)_{2}\left[\mathrm{Pt}(\mathrm{qS})_{2}\right] \cdot(\mathrm{TCE})_{2}$ (black prism; Phase A) and (TMTTF) ${ }_{3}\left[\operatorname{Pt}(\mathrm{qS})_{2}\right]$ (black plate; Phase B) were obtained on the anode.

Crystallography. X-ray crystal structure collections were performed on an APEXII Bruker-AXS diffractometer equipped with a CCD camera and a graphite-monochromated Mo-K $\alpha$ radiation source $(\lambda=$ $0.71073 \AA$ ) at $150 \mathrm{~K}$. Details of the structural analyses are summarized in Table 1 . Absorption corrections were performed with SADABS. Structures were solved by direct methods using the SIR97 program, ${ }^{42}$ and then refined with full-matrix least-squares methods based on $\mathrm{F}^{2}$ (SHELXL-97) ${ }^{43}$ with the aid of the WINGX program . ${ }^{44}$ All non-hydrogen atoms were refined with anisotropic atomic displacement parameters. $\mathrm{H}$ atoms were finally included in their calculated positions. Crystallographic data were deposited as CCDC 1997195 (Phase A) and 1997196 (Phase B).

Resistivity measurements. Gold contacts were evaporated on the single crystals and gold wires (17 $\mu \mathrm{m}$ diameter) were glued with silver paste on those contacts. Because of very high resistance values, two-probe DC measurements were performed under vacuum, applying a constant voltage of $0.2 \mathrm{~V}$ and measuring the current using a Keithley 6487 Picoammeter / Voltage Source. Low temperature was provided by a home-made cryostat equipped with a $4 \mathrm{~K}$ pulsetube using a cernox in good thermal contact with the samples as thermometer.

Infrared and Raman spectroscopy. To assign vibrational bands of $\left[\mathrm{Pt}(\mathrm{qS})_{2}\right]^{2-}$ anions, we have performed IR and Raman spectra of two salts $\left[\mathrm{Pt}(\mathrm{qS})_{2}\right] \mathrm{K}_{2}$ and $\left[\mathrm{Pt}(\mathrm{qS})_{2}\right] \mathrm{Na}_{2}$ (Cf Figures S3-S4 and Table S1 in ESI). Their Raman spectra were measured for powders using green light $(\lambda=514.5 \mathrm{~nm})$ from an argon-ion laser and IR spectra were recorded for powders dispersed in $\mathrm{KBr}$ pellets. Additionally, quantum chemical calculations of normal modes of $\left[\mathrm{Pt}(\mathrm{qS})_{2}\right]^{2-}$ anions, were performed with Gaussian 03 program (Gaussian, Inc., Pittsburgh, PA). ${ }^{45}$ The equilibrium geometry with no symmetry constrains and harmonic vibrational transitions were evaluated with the B3LYP density functional theory using a LanL2DZ basis set. Then, we calculated the IR and Raman scattering intensities and modelled respective vibrational spectra of $\left[\mathrm{Pt}(\mathrm{qS})_{2}\right]^{2-}$ anions.

Room temperature Raman spectra of (TMTTF $)_{3}\left[\mathrm{Pt}(\mathrm{qS})_{2}\right]$ crystals were measured in a backward scattering geometry using Labram HR Horiba 800 Jobin Yvon with a He-Ne laser $(\lambda=632.8 \mathrm{~nm})$ and an argon-ion laser $(\lambda=514.5 \mathrm{~nm})$. The exciting laser beam was polarized but the polarization of scattered light was not studied. The spectra were recorded with the spectral resolution of $2 \mathrm{~cm}^{-1}$. To avoid sample overheating, the power of the laser beam was reduced down to about $0.05-0.1 \mathrm{~mW}$. Polarized reflectance measurements of $(\mathrm{TMTTF})_{3}\left[\mathrm{Pt}(\mathrm{qS})_{2}\right]$ single crystals were performed in the frequency range from 700 to $12000 \mathrm{~cm}^{-1}$ using Fourier transform FT-IR Bruker Equinox 55 spectrometer equipped with a Bruker microscope Hyperion 2000. The optical conductivity spectra were determined by Kramers-Kronig analysis of the reflectance data. For low temperature IR measurements (down to $T=50 \mathrm{~K}$ ), the samples were mounted in the Oxford Instruments continuous flow helium cryostat.

Table 1. Crystallographic data

\begin{tabular}{|c|c|c|}
\hline & $(\mathrm{TMTTF})_{2}\left[\mathrm{Pt}(\mathrm{qS})_{2}\right] \cdot(\mathrm{TCE})_{2}$ & $(\mathrm{TMTTF})_{3}\left[\mathrm{Pt}(\mathrm{qS})_{2}\right]$ \\
\hline Formula & $\mathrm{C}_{42} \mathrm{H}_{40} \mathrm{Cl}_{6} \mathrm{~N}_{2} \mathrm{O}_{8} \mathrm{PtS}_{10}$ & $\mathrm{C}_{48} \mathrm{H}_{46} \mathrm{~N}_{2} \mathrm{O}_{8} \mathrm{PtS}_{14}$ \\
\hline $\mathrm{FW}\left(\mathrm{g} \cdot \mathrm{mol}^{-1}\right)$ & 1429.14 & 1422.79 \\
\hline System & triclinic & monoclinic \\
\hline Space group & $\mathrm{P}-1$ & $\mathrm{C} 2 / \mathrm{m}$ \\
\hline$a(\AA)$ & $9.8814(4)$ & $22.6764(15)$ \\
\hline$b(\AA)$ & $12.1332(4)$ & $9.9976(6)$ \\
\hline$c(\AA)$ & $12.3986(5)$ & $12.7217(9)$ \\
\hline$\alpha(\mathrm{deg})$ & $90.2050(10)$ & 90.00 \\
\hline$B$ (deg) & $113.0050(10)$ & $110.900(3)$ \\
\hline$v$ (deg) & $109.1680(10)$ & 90.00 \\
\hline$V\left(\AA^{3}\right)$ & $1277.47(9)$ & $2694.4(3)$ \\
\hline$T(\mathrm{~K})$ & $150(2)$ & $150(2)$ \\
\hline$Z$ & 1 & 2 \\
\hline$D_{\text {calc }}\left(\mathrm{g} \cdot \mathrm{cm}^{-1}\right)$ & 1.858 & 1.754 \\
\hline$\mu\left(\mathrm{mm}^{-1}\right)$ & 3.522 & 3.201 \\
\hline Total refls & 19611 & 11442 \\
\hline Abs corr & multi-scan & multi-scan \\
\hline$T_{\min }, T_{\max }$ & $0.810,0.869$ & $0.794,0.968$ \\
\hline$\vartheta_{\max }\left({ }^{\circ}\right)$ & 27.525 & 27.498 \\
\hline Uniq refls & 5787 & 3259 \\
\hline$R_{\text {int }}$ & 0.0397 & 0.0396 \\
\hline Uniq refls $[I>2 \sigma(I)]$ & 5510 & 3056 \\
\hline$R_{1}$ & 0.0294 & 0.0308 \\
\hline$w R_{2}$ (all data) & 0.0577 & 0.0593 \\
\hline GOF & 1.048 & 1.017 \\
\hline Res. dens. $\left(\mathrm{e} \AA^{-3}\right)$ & $-0.764,+1.04$ & $-0.984,+0.78$ \\
\hline
\end{tabular}

\section{Results}

\subsection{Crystal structures}

The electrocrystallization of TMTTF was performed in 1,1,2trichloroethane (TCE), in the presence of the tretraphenylphosphonium salt of $\left[\mathrm{Pt}(\mathrm{qS})_{2}\right]^{2-},\left(\mathrm{Ph}_{4} \mathrm{P}\right)_{2}\left[\mathrm{Pt}(\mathrm{qS})_{2}\right]$ as electrolyte. ${ }^{40}$ It afforded simultaneously on the anode crystals with two different habits, named hereafter as Phase A and Phase B. Phase A crystallizes in the triclinic system, space group $\mathrm{P}-1$, with one TMTTF and one solvent molecule (1,1,2-trichloroethane) in general position and one $\left[\mathrm{Pt}(\mathrm{qS})_{2}\right]^{2-}$ complex on inversion centre, hence a $(\mathrm{TMTTF})_{2}\left[\mathrm{Pt}(\mathrm{qS})_{2}\right] \cdot(\mathrm{TCE})_{2}$ stoichiometry, implying that each TMTTF molecule is in its monocationic state, TMTTF $^{+\bullet}$. This is also confirmed by the intramolecular bond lengths within the TTF core (Table 2), with a particularly long central $\mathrm{C}=\mathrm{C}$ bond at 1.395(4) $\AA$. As shown in Figure 1, the $\mathrm{TMTTF}^{+\bullet}$ cations associate into face-toface, almost eclipsed dicationic dyads, alternating with the $\left[\mathrm{Pt}(\mathrm{qS})_{2}\right]^{2-}$ complex along the $(a-b)$ direction. We note also the presence of a short $\mathrm{Cl}_{2} \mathrm{C}-\mathrm{H} \cdot \cdots \mathrm{O}-\mathrm{SO}_{2}$ hydrogen bond between the most acidic proton of TCE and one oxygen atom of the sulfonate group, with a short $\mathrm{H} \cdots \mathrm{O}$ distance at 2.247(2) $\AA$ (Figure 2), to be compared with the sum of van der Waals radii of $\mathrm{H}$ and $\mathrm{O}(2.72 \AA)$ and a notable directionality as the $\mathrm{C}-\mathrm{H} \bullet \bullet \mathrm{O}$ angle amounts to 
$150.3(2)^{\circ}$. Other $\mathrm{C}-\mathrm{H} \bullet \bullet \mathrm{O}$ interactions are observed between the methyl groups of the TMTTF cation and one oxygen atom of the sulfonate anion, giving rise to a characteristic $R_{2}^{1}(7)$ cyclic motif. Altogether, the TMTTF dyads are fully isolated from each other in the structure. Conductivity measurements confirm this full charge transfer as the crystals are fully insulating with $\sigma_{R T} \approx 3 \times 10^{-9} \mathrm{~S} \mathrm{~cm}^{-}$ 1

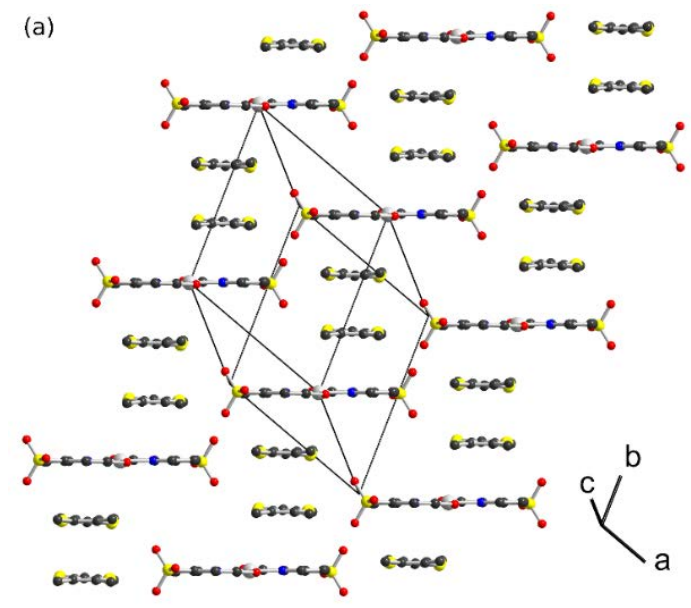

(b)

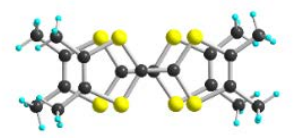

Figure 1. Phase A: (a) Overlap between $\mathrm{TMTTF}^{+\bullet}$ radical cations; (b) detail of one $(a, b)$ plane. Hydrogen atoms and TCE molecules have been omitted for clarity.

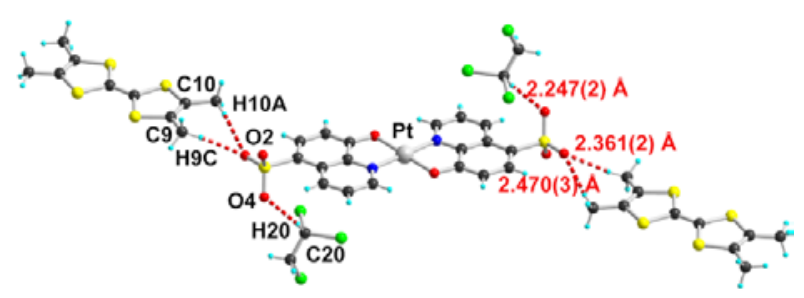

Figure 2. $\mathrm{C}-\mathrm{H}$ hydrogen bonds with the anionic sulfonate moieties in Phase A. $\mathrm{H}_{20} \bullet \bullet \mathrm{O}_{4}:$ 2.247(2) $\AA, \mathrm{C}_{20}-\mathrm{H}_{20} \bullet \bullet \mathrm{O}_{4}: 150.3(2)^{\circ}$; $\mathrm{H}_{9 \mathrm{C}} \bullet \bullet \mathrm{O}_{2}: 2.361(2) \AA, \mathrm{C}_{9}-\mathrm{H}_{9 \mathrm{C}} \bullet \bullet \bullet \mathrm{O}_{2}: 174.4(2)^{\circ} ; \mathrm{H}_{10 A} \bullet \bullet \mathrm{O}_{2}: 2.470(2)$ Å, $\mathrm{C}_{10}-\mathrm{H}_{10 \mathrm{~A}} \bullet \bullet \mathrm{O}_{2}: 167.2(2)^{\circ}$.

Phase B crystallizes in the monoclinic system, space group $\mathrm{C} 2 / \mathrm{m}$, with the platinum complex on a $2 / \mathrm{m}$ site, lying flat on the mirror plane, one TMTTF on another $2 / \mathrm{m}$ site, but with the mirror plane perpendicular to the molecule and along its long axis and noted Mol. 1, and a second TMTTF molecule on a mirror plane, also perpendicular to the molecule and along its long axis, noted Mol. 2. Altogether, it corresponds to a $0.25\left[\mathrm{Pt}(\mathrm{qS})_{2}\right], 0.25 \mathrm{Mol} .1$ and 0.5 Mol.2 moieties in the asymmetric unit, that is a (TMTTF) $)_{3}\left[\mathrm{Pt}(\mathrm{qS})_{2}\right]$ stoichiometry, with three TMTFF molecules for one dianion. In the structure, the TMTTF are organized into trimers, with inversioncentred Mol. 1 sandwiched between two Mol. 2. These trimers stack along the $c$ axis while they are fully isolated from each other in the $(a, b)$ plane. Comparison of the intramolecular bond lengths within the TTF core in Mol. 1 and Mol. 2 (Table 2) tends to indicate that the central, inversion centred Mol. 1 bears a tentative +1 charge while the charge of the outer Mol. 2 is close to +0.5 . Note that this tentative charge distribution is associated with a planar geometry for
Mol. 1 while Mol. 2 adopts a boat conformation with a folding of one dithiole ring by $7.6(1)^{\circ}$. As shown in Figure 4, we also note a set of weak $\mathrm{C}-\mathrm{H} \cdot \cdots \mathrm{O}$ hydrogen bonding interactions, with the $\boldsymbol{R}_{\mathbf{2}}^{\mathbf{1}}(\mathbf{7})$ cyclic motif but with slightly longer $\mathrm{H} \cdots \mathrm{O}$ distances. At variance with Phase A, Phase B is semiconducting (Figure S1 in ESI), with $\sigma_{R T}$ value of $4 \times 10^{-5} \mathrm{~S} \mathrm{~cm}^{-1}$ and an activation energy of $1620 \mathrm{~K}(0.14$ $\mathrm{eV})$.
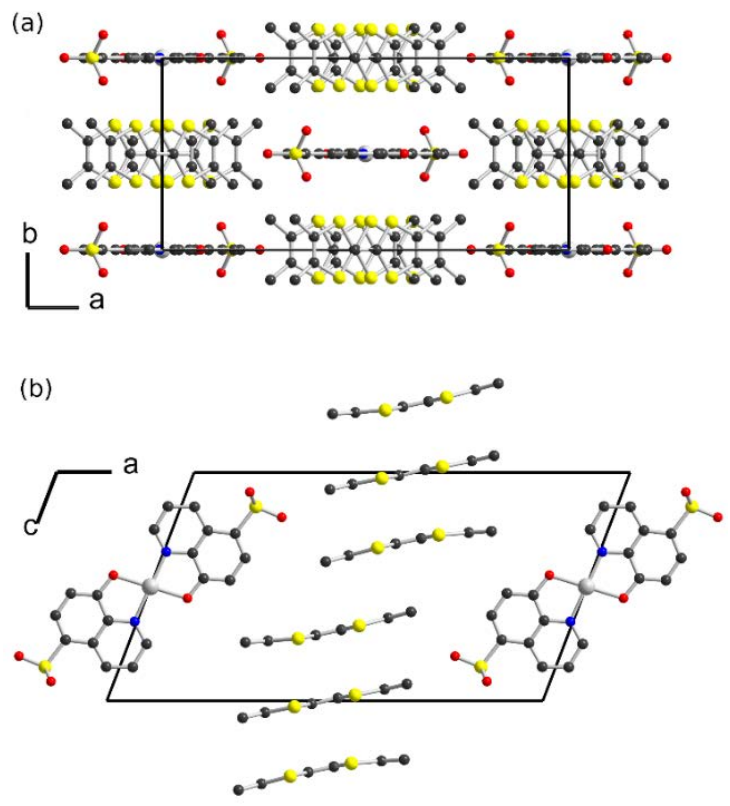

Figure 3. Projection views of the unit cell of Phase B: (a) along $c$ direction, (b) along $b$ direction. Hydrogen atoms were omitted for clarity.

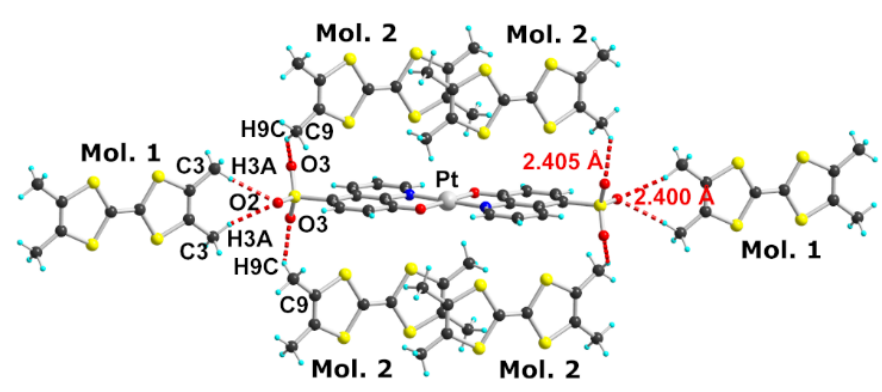

Figure 4. $\mathrm{C}-\mathrm{H}$ hydrogen bonds with the anionic sulfonate moieties in Phase B. $\mathrm{H}_{3 \mathrm{~A}} \bullet \bullet \mathrm{O}_{2}: 2.400$ (3) $\AA, \mathrm{C}_{3}-\mathrm{H}_{3 \mathrm{~A}} \bullet \bullet \mathrm{O}_{2}: 156.9(2)^{\circ}$, $\mathrm{H}_{9 \mathrm{C}} \bullet \bullet \mathrm{O}_{3}: 2.405(2) \AA$ A $, \mathrm{C}_{9}-\mathrm{H}_{9 \mathrm{C}} \bullet \bullet \mathrm{O}_{3}: 148.2(2)^{\circ}$.

The presence in Phase $\mathrm{B}$ of trimeric dicationic (TMTTF) ${ }_{3}{ }^{2+}$ moieties raises questions about the actual charge distribution within the three TMTTF molecules. Only a few TMTTF salts have been reported in the literature, which exhibit the same trimeric motifs with the charge +2 . They are obtained upon association with dianionic counter ions, such as $\left[\mathrm{Ti}_{2} \mathrm{~F}_{10}\right]^{2-}{ }^{50}$ or $\left[\mathrm{Re}_{2} \mathrm{Cl}_{8}\right]^{2-}{ }^{51}$ In both salts, the charge is distributed non-uniformly among TMTTF molecules: for the $\mathrm{Ti}_{2} \mathrm{~F}_{10}$ salt $(+0.5,+1,+0.5)$ and the $\operatorname{Re}_{2} \mathrm{Cl}_{8}$ salt $(0,+1,+1)$. This charge distribution within the trimer can be evaluated in a more quantitative way by using the linear relationship between the 
charge and a structural parameter $\delta$ defined as $\delta=(\mathrm{b}+\mathrm{c})-(\mathrm{a}+\mathrm{d})$ where a-d are intramolecular bond lengths (see Table 2). Such correlations were already established for BEDT-TTF, TTF and TMTSF, ${ }^{52}$ but not TMTTF. Using the reference compounds

Table 2. Averaged intramolecular bond lengths in the TTF core in the two salts and in reference compounds. The $\delta$ parameter used to estimate the TMTTF charge $\left(\rho_{\text {calcd }}\right)$ is defined as $(b+c)-(a+d)$ where a-d are averaged intramolecular distances (see text for details). relation which writes as $\rho=A-$

\begin{tabular}{|c|c|c|c|c|c|c|c|c|}
\hline & $a(\AA ̊)$ & $b(\AA ̊)$ & $c(\AA)$ & $d(\AA \AA)$ & $\delta$ param. & $\rho_{\text {cryst }}$ & $\rho_{\text {calcd }}$ & Ref. \\
\hline$(\mathrm{TMTTF})\left(\mathrm{ClO}_{4}\right)_{2}$ & 1.452 & 1.680 & 1.711 & 1.365 & 0.574 & +2 & +1.98 & 46 \\
\hline$(\mathrm{TMTTF})\left(\mathrm{BF}_{4}\right)$ & 1.404 & 1.715 & 1.737 & 1.355 & 0.693 & +1 & +1.08 & 47 \\
\hline Phase A & $1.395(3)$ & $1.714(3)$ & $1.745(3)$ & $1.346(3)$ & 0.704 & +1 & +0.99 & this work \\
\hline Phase B, mol. 1 & $1.400(7)$ & $1.706(3)$ & $1.737(4)$ & $1.350(4)$ & 0.693 & $+1 ?$ & +1.08 & this work \\
\hline Phase B, mol. 2 & $1.361(8)$ & $1.743(3)$ & $1.750(3)$ & $1.349(4)$ & 0.783 & $+0.5 ?$ & +0.39 & this work \\
\hline$(\mathrm{TMTTF})_{2} \mathrm{AsF}_{6}$ & 1.341 & 1.740 & 1.739 & 1.354 & 0.784 & +0.5 & +0.39 & \\
\hline TMTTF $^{0}$ & 1.359 & 1.762 & 1.767 & 1.343 & 0.827 & 0 & +0.06 & 49 \\
\hline
\end{tabular}

$B \times \delta$ with $A=6.3382$ and $B=7.5911$. As shown in Table 2, the inversion centred Mol. 1 is found indeed with a calculated charge close to +1 (1.08) while the charge of the outer Mol. 2 is close to $+0.5(0.39)$ and the sum for the three molecules $(1.08+2 \times 0.39=$ 1.86) close to the +2 charge imposed by the stoichiometry. To address this charge distribution in more details, we have performed extensive IR and Raman investigations of the trimeric phase, as reported below.

\subsection{Raman spectra of (TMTTF $)_{3}\left[\operatorname{Pt}(\mathrm{qS})_{2}\right]$}

Room temperature Raman spectra of the salt (TMTTF $)_{3}\left[\mathrm{Pt}(\mathrm{qS})_{2}\right]_{2}$ for two perpendicular polarizations of the exciting laser beam $(\lambda=514.5 \mathrm{~nm})$, i.e. parallel and perpendicular to the stacking $c$-axis, are shown in Figure 5 . The observed vibrational features of the TMTTF molecules in (TMTTF $)_{3}\left[\mathrm{Pt}(\mathrm{qS})_{2}\right]_{2}$ have been assigned with the help of experimental and calculated IR and Raman spectra of the $\left[\mathrm{Pt}(\mathrm{qS})_{2}\right]^{2-}$ dianion (Figures S3, S4, and Table S1 in ESI) since the spectra are dominated by vibrational bands related to $\left[\operatorname{Pt}(\mathrm{qS})_{2}\right]^{2-}$ anions. Additionally, in the spectrum some bands attributed to TMTTF molecules can be clearly identified. The observed vibrational bands together with proposed assignments are collected in Table 3.

To determine the charge distribution among molecules in the TMTTF trimers, we focused our attention on vibrational features observed in the frequency ranges of $\mathrm{C}=\mathrm{C}$ stretching and $\mathrm{C}-\mathrm{S}$ ring breathing vibrations since these modes are most sensitive to the charge residing on donor molecules. The neutral $\mathrm{TMTTF}^{0}$ has two Raman active $\mathrm{C}=\mathrm{C}$ stretching modes $v_{3}\left(\mathrm{a}_{\mathrm{g}}\right)=639 \mathrm{~cm}^{-1}$ and $v_{4}\left(\mathrm{a}_{\mathrm{g}}\right)$ $=1538 \mathrm{~cm}^{-1}$ and one IR active mode $v_{28}\left(\mathrm{~b}_{1 \mathrm{u}}\right)=1627 \mathrm{~cm}^{-1} \cdot{ }^{53,54}$ When the ionization degree increases, the positions of these modes shift linearly towards lower wavenumbers: for the fully ionized TMTTF ${ }^{+}$ molecule the shift equals to $72 \mathrm{~cm}^{-1}$ for $v_{3}\left(\mathrm{a}_{\mathrm{g}}\right), 120 \mathrm{~cm}^{-1}$ for $v_{4}\left(\mathrm{a}_{\mathrm{g}}\right)$, and $80 \mathrm{~cm}^{-1}$ for $v_{28}\left(\mathrm{~b}_{1 \mathrm{u}}\right)$. However, in Raman spectra only the $v_{3}\left(\mathrm{a}_{\mathrm{g}}\right)$ mode can be used for determination of the charge density since the $v_{4}\left(\mathrm{a}_{\mathrm{g}}\right)$ mode is nearly independent on charge due to strong coupling with electrons in TMTTF stacks (or clusters). ${ }^{55}$ Recently, it has been shown that two $\mathrm{C}-\mathrm{S}$ stretching ring breathing modes, i.e. symmetric $v_{10}\left(\mathrm{a}_{\mathrm{g}}\right)=494 \mathrm{~cm}^{-1}$ and antisymmetric $v_{35}\left(\mathrm{a}_{\mathrm{g}}\right)=439 \mathrm{~cm}^{-1}$ (for $\mathrm{TMTTF}^{0}$ ), can be also useful for determination of the charge distribution in TMTTF stacks. ${ }^{56}$

On the ionization of TMTTF form 0 to +1 the $v_{10}\left(\mathrm{a}_{\mathrm{g}}\right)$ mode shifts

linearly by $29 \mathrm{~cm}^{-1}$ towards higher wavenumbers.

The Raman spectra of (TMTTF) $)_{3}\left[\operatorname{Pt}(\mathrm{qS})_{2}\right]$ for polarization $E \perp \mathrm{C}$ within the frequency region $1200-1700 \mathrm{~cm}^{-1}$ are displayed in collected in Table 2 (See Figure S2 in ESI), we found a linear

ule at

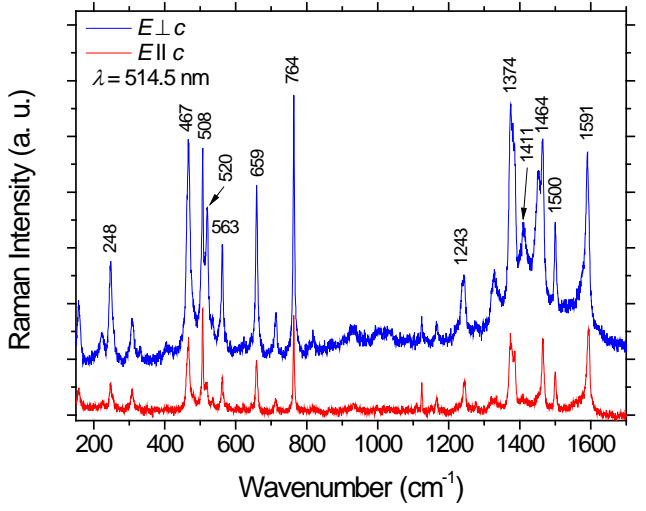

Figure 5. Room temperature Raman spectra of the salt $(\mathrm{TMTTF})_{3}\left[\mathrm{Pt}(\mathrm{qS})_{2}\right]$ for the laser beam polarized parallel and perpendicular to the $c$-axis (excitation $\lambda=514.5 \mathrm{~nm}$ ).

1244, 1328 (1333), 1374, 1411 (1413), 1464, and $1500 \mathrm{~cm}^{-1}$, one can also distinguish two bands at 1453 and $1591 \mathrm{~cm}^{-1}$ that we assign to the $\mathrm{C}=\mathrm{C}$ stretching modes of TMTTF $v_{4}\left(\mathrm{a}_{\mathrm{g}}\right)$ and $v_{3}\left(\mathrm{a}_{\mathrm{g}}\right)$, respectively. Assuming the liner dependence of band position against the charge on molecule, the band wavenumber $v_{3}\left(\mathrm{a}_{\mathrm{g}}\right)=1591 \mathrm{~cm}^{-1}$ corresponds to the charge $+0.66,{ }^{54}$ however this value is probably not very reliable due to strong overlap with a band of $\left[\mathrm{Pt}(\mathrm{qS})_{2}\right]^{2-}$. If the charge distribution inside TMTTF trimers is non-uniform, the $v_{3}\left(\mathrm{a}_{\mathrm{g}}\right)$ mode should be split but an eventual splitting is probably hidden in the broad vibrational feature centered at $1591 \mathrm{~cm}^{-1}$. On the other hand, the band position $v_{4}\left(\mathrm{a}_{\mathrm{g}}\right)=1453 \mathrm{~cm}^{-1}$ corresponds to the charge +0.71 . This value is to be expected considering that, due to strong coupling with electrons, the band provides information about an average charge density in TMTTF trimer. The band at $1385 \mathrm{~cm}^{-1}$ is attributed to the $v_{6}\left(\mathrm{a}_{\mathrm{g}}\right)$ mode (symmetrical vibration of $\mathrm{CH}_{3}$ groups). More reliable information about the charge distribution can be obtained from the analysis of the ring breathing $v_{10}\left(\mathrm{a}_{\mathrm{g}}\right)$ mode. In 
the frequency range $280-700 \mathrm{~cm}^{-1}$ (Figure 6b) we identify three bands at 507, 514, $520 \mathrm{~cm}^{-1}$ assigned to the $v_{10}\left(\mathrm{a}_{\mathrm{g}}\right)$ mode of TMTTF molecules with various charges (see also Figure 7) and a band at 562 $\mathrm{cm}^{-1}$ attributed to the $v_{9}\left(\mathrm{a}_{\mathrm{g}}\right)$ mode (S-C-CH stretching). ${ }^{53,}$, The position of the $v_{10}\left(\mathrm{a}_{\mathrm{g}}\right)$ mode also depends linearly on charge, therefore the three $v_{10}\left(\mathrm{a}_{\mathrm{g}}\right)$ peaks correspond to TMTTF molecules with charges $+0.45,+0.69$, +0.90 , respectively, ${ }^{56}$ which is consistent with the initial assignment, based on the crystallographic investigations, of $+0.5,+1,+0.5$ within the trimer. Additionally, one can find bands assigned to the dianion at 308, 467 and $659 \mathrm{~cm}^{-1}$ which show a considerable intensity enhancement for the excitation $\lambda=514.5 \mathrm{~nm}$.
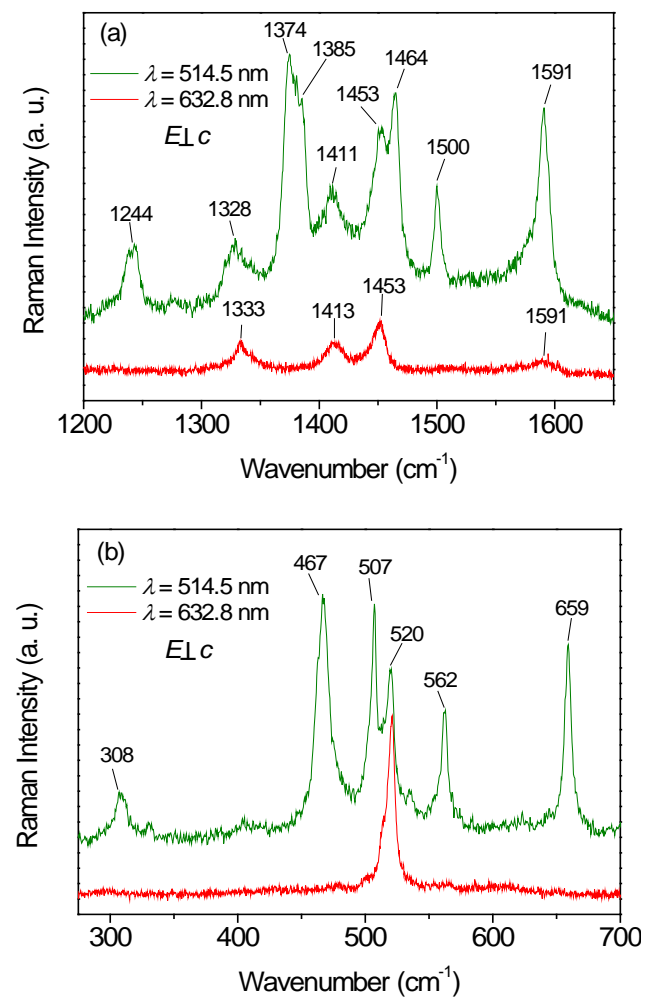

Figure 6. Room temperature Raman spectra of the salt $(\mathrm{TMTTF})_{3}\left[\mathrm{Pt}(\mathrm{qS})_{2}\right]$ within the region of $\mathrm{C}=\mathrm{C}(\mathrm{a})$ and $\mathrm{C}-\mathrm{S}$ stretching $(\mathrm{b})$ modes for the green $(\lambda=514.5 \mathrm{~nm})$ and $\operatorname{red}(\lambda=632.8 \mathrm{~nm})$ excitations. The electrical vector of the laser beams is perpendicular to the $c$-axis.

\subsection{Infrared reflectance of $(\mathrm{TMTTF})_{3}\left[\operatorname{Pt}(\mathrm{qS})_{2}\right]$}

Figure 8 presents the room temperature reflectance spectra of (TMTTF $)_{3}\left[\mathrm{Pt}(\mathrm{qS})_{2}\right]$, recorded for two perpendicular polarizations of the incident IR beam, and corresponding optical conductivity spectra determined by Kramers-Kronig analysis. The optical response is one-dimensional in agreement with interactions calculated on basis of the crystal structure. For polarization parallel to TMTTF stacks $E \| c$ the spectrum displays a broad electronic absorption (centred at about $3750 \mathrm{~cm}^{-1}$ ) associated with intra-trimer charge-transfer excitations. Below $1700 \mathrm{~cm}^{-1}$, the spectra for both polarizations show many vibrational features related with both the donor and acceptor modes (Table 3). The strongest bands for polarization $E \|_{c}$ are a consequence of coupling of the totally symmetric $a_{g}$ modes of TMTTF with charge transfer transitions.

In order to shed more light on both vibrational and electronic features of the (TMTTF $)_{3}\left[\operatorname{Pt}(\mathrm{qS})_{2}\right]$ spectra and eventual phase transitions, polarized reflectance measurements as a function of temperature have been performed. Temperature dependence of the IR reflectance and the optical conductivity spectra for polarization E $\| \mathrm{c}$ are shown in Figure S5a in ESI and Figure 9, respectively. On temperature decreasing the charge-transfer band slightly shifts towards higher wavenumbers and it is better seen that this band consists of two components at least. At $T=50 \mathrm{~K}$, one can distinguish two bands centred at 3950 and $4650 \mathrm{~cm}^{-1}$ which should be related to intra-trimer charge-transfer transitions. Since interactions between

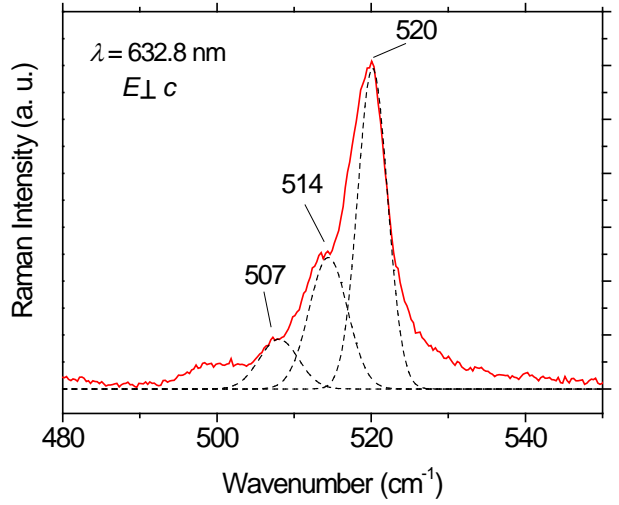

Figure 7. Raman bands related to the $v_{10}\left(\mathrm{a}_{\mathrm{g}}\right)$ mode (excitation $\lambda=$ $632.8 \mathrm{~nm}$ ). Dashed lines show a band deconvolution by using the Lorentz functions.
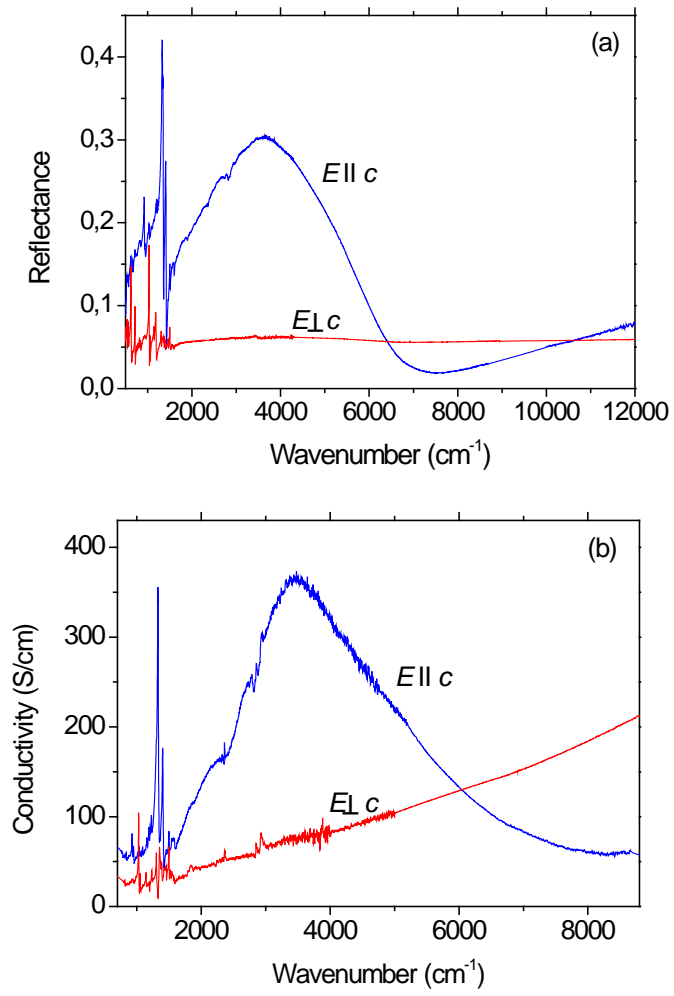

Figure 8. Room temperature IR reflectance (a) and optical conductivity (b) spectra of $(\mathrm{TMTTF})_{3}\left[\mathrm{Pt}(\mathrm{qS})_{2}\right]$ crystals. The reflectance was recorded from the (010) crystal face for the electrical vector of IR beam polarized parallel $(E \| C)$ and perpendicular $(E \perp C)$ to the $c$-axis.

neighbouring trimers in TMTTF stacks are very weak, a possible contribution of the inter-trimer charge-transfer excitations should be excluded. 
The vibrational spectra for polarization $E \| c$ are dominated by a strong and broad vibrational feature between 1300 and $1420 \mathrm{~cm}^{-1}$ which is a result of electron-molecular vibration (EMV) coupling of the $v_{4}\left(\mathrm{a}_{\mathrm{g}}\right)$ mode (Figure 10 and Figure S5b in ESI). The apparent doublet structure of this band is a consequence of the strong antiresonance centred at $1370 \mathrm{~cm}^{-1}$ related to the $v_{6}\left(\mathrm{a}_{\mathrm{g}}\right)$ mode (symmetrical vibration of $\mathrm{CH}_{3}$ groups). Such antiresonance superimposed on the $\mathrm{C}=\mathrm{C}$ vibronic feature is common not only Table 3 Vibrational bands of the $(\mathrm{TMTTF})_{3}\left[\mathrm{Pt}(\mathrm{qS})_{2}\right]$ salt at $\mathrm{T}=295 \mathrm{~K}$. for TMTTF salts but also for salts formed by other TTF derivatives. The

\begin{tabular}{|c|c|c|c|c|c|c|}
\hline \multicolumn{4}{|c|}{$(\mathrm{TM} \text { TTF })_{3}\left[\mathrm{Pt}(\mathrm{qS})_{2}\right]$} & \multirow{3}{*}{$\begin{array}{l}\text { TMTTF }^{0} \\
\text { exp. }{ }^{*} \\
\left(\mathrm{~cm}^{-1}\right)\end{array}$} & \multirow{3}{*}{$\begin{array}{l}\text { TMTTF }^{+} \\
\text {exp.* } \\
\left(\mathrm{cm}^{-1}\right)\end{array}$} & \multirow{3}{*}{ Assignment ** } \\
\hline \multicolumn{2}{|c|}{ Infrared $\left(\mathrm{cm}^{-1}\right)$} & \multicolumn{2}{|c|}{$\begin{array}{c}\text { Raman }\left(\mathrm{cm}^{-1}\right) \\
\text { Excit. } \lambda=514.5 \mathrm{~nm}\end{array}$} & & & \\
\hline$E \| c$ & $E \perp C$ & $E \| c$ & $E \perp C$ & & & \\
\hline 1653 & 1655 & - & - & - & - & ? \\
\hline 1647 & - & - & - & - & - & {$\left[\mathrm{Pt}(\mathrm{qS})_{2}\right]^{2-}$} \\
\hline 1597 & - & 1593 & 1591 & 1639 & 1567 & $v_{3}\left(\mathrm{a}_{\mathrm{g}}\right)$ and $\left[\mathrm{Pt}(\mathrm{qS})_{2}\right]^{2-}$ \\
\hline 1584 & 1585 & - & - & - & - & $v_{28}\left(b_{1 u}\right), q=+0.84$ \\
\hline 1576 & 1574 & - & - & 1627 & 1547 & $v_{28}\left(b_{1 u}\right), q=+0.64$ \\
\hline 1551 & 1551 & - & - & - & - & $v_{28}\left(b_{1 u}\right), q=+0.54$ \\
\hline 1500 & 1499 & 1500 & 1500 & - & - & {$\left[\mathrm{Pt}(\mathrm{qS})_{2}\right]^{2-}$} \\
\hline 1460 & 1457 & 1465 & 1464 & - & - & {$\left[\mathrm{Pt}(\mathrm{qS})_{2}\right]^{2-}$} \\
\hline $1420-1300$ & - & $1453^{a}$ & 1453 & 1538 & 1418 & $v_{4}\left(a_{g}\right)$ \\
\hline- & 1410 & - & 1411 & - & - & {$\left[\mathrm{Pt}(\mathrm{qS})_{2}\right]^{2-}$} \\
\hline 1388 & - & - & - & - & - & {$\left[\mathrm{Pt}(\mathrm{qS})_{2}\right]^{2-}$} \\
\hline$\approx 1370$ & 1389 & $1385^{b}$ & $1385^{\mathrm{b}}$ & - & - & $v_{6}\left(\mathrm{a}_{\mathrm{g}}\right) \operatorname{dip} I R$ \\
\hline- & 1368 & $1374^{b}$ & $1374^{b}$ & - & - & {$\left[\mathrm{Pt}(\mathrm{qS})_{2}\right]^{2-}$} \\
\hline - & - & $1333^{a}$ & $1328^{\mathrm{a}}$ & - & - & {$\left[\mathrm{Pt}(\mathrm{qS})_{2}\right]^{2-}$} \\
\hline - & 1319 & 1319 & $1321^{c}$ & - & - & {$\left[\mathrm{Pt}(\mathrm{qS})_{2}\right]^{2-}$} \\
\hline- & 1305 & - & - & - & - & {$\left[\mathrm{Pt}(\mathrm{qS})_{2}\right]^{2-}$} \\
\hline- & - & 1244 & 1244 & - & - & {$\left[\mathrm{Pt}(\mathrm{qS})_{2}\right]^{2-}$} \\
\hline 1230 & 1234 & - & - & - & - & {$\left[\mathrm{Pt}(\mathrm{qS})_{2}\right]^{2-}$} \\
\hline 1212 & 1207 & - & - & - & - & {$\left[\mathrm{Pt}(\mathrm{qS})_{2}\right]^{2-}$} \\
\hline 1191 & 1192 & - & - & 1183 & 1185 & $v_{48}\left(b_{2 u}\right)$ \\
\hline 1161 & 1161 & 1167 & 1167 & - & - & {$\left[\mathrm{Pt}(\mathrm{qS})_{2}\right]^{2-}$} \\
\hline- & 1144 & 1151 & - & - & - & {$\left[\mathrm{Pt}(\mathrm{qS})_{2}\right]^{2-}$} \\
\hline - & - & 1124 & 1124 & - & - & {$\left[\mathrm{Pt}(\mathrm{qS})_{2}\right]^{2-}$} \\
\hline 1091 & 1090 & - & - & 1092 & 1104 & $v_{7}\left(a_{g}\right)$ \\
\hline 1056 & 1053 & - & - & - & - & {$\left[\mathrm{Pt}(\mathrm{qS})_{2}\right]^{2-}$} \\
\hline 1033 & 1032 & 1034 & 1035 & - & - & {$\left[\mathrm{Pt}(\mathrm{qS})_{2}\right]^{2-}$} \\
\hline 940 & 940 & 950,928 & - & 934 & 941 & $v_{8}\left(a_{g}\right)$ \\
\hline 925 & 920 & - & 933 & 935 & 935 & $v_{32}\left(b_{1 u}\right)$ \\
\hline 839 & 839 & - & - & - & - & $?$ \\
\hline- & 815 & 818 & 819 & - & - & {$\left[\mathrm{Pt}(\mathrm{qS})_{2}\right]^{2-}$} \\
\hline 759 & 759 & 764 & 764 & - & - & {$\left[\mathrm{Pt}(\mathrm{qS})_{2}\right]^{2-}$} \\
\hline 717 & 714 & 712 & 713 & - & - & {$\left[\mathrm{Pt}(\mathrm{qS})_{2}\right]^{2-}$} \\
\hline 669 & 668 & 659 & 659 & - & - & {$\left[\mathrm{Pt}(\mathrm{qS})_{2}\right]^{2-}$} \\
\hline- & - & 562 & 562 & 560 & 566 & $v_{9}\left(a_{g}\right)$ \\
\hline- & - & 535 & - & - & - & {$\left[\mathrm{Pt}(\mathrm{qS})_{2}\right]^{2-}$} \\
\hline - & - & $520^{\mathrm{a}}$ & $520^{a}$ & - & - & $v_{10}\left(a_{g}\right), q=+0.90$ \\
\hline- & - & $514^{a}$ & $514^{a}$ & 494 & 523 & $v_{10}\left(a_{\mathrm{g}}\right), q=+0.69$ \\
\hline - & - & $507^{\mathrm{a}}$ & $507^{a}$ & - & - & $v_{10}\left(a_{g}\right), q=+0.45$ \\
\hline- & - & 467 & 467 & - & - & {$\left[\mathrm{Pt}(\mathrm{qS})_{2}\right]^{2-}$} \\
\hline - & - & 307 & 308 & - & - & {$\left[\mathrm{Pt}(\mathrm{qS})_{2}\right]^{2-}$} \\
\hline- & - & 247 & 248 & - & - & {$\left[\mathrm{Pt}(\mathrm{qS})_{2}\right]^{2-}$} \\
\hline- & - & 157 & 157 & - & - & {$\left[\mathrm{Pt}(\mathrm{qS})_{2}\right]^{2-}$} \\
\hline
\end{tabular}

* Ref. ${ }^{53,54}$

** assignment of the $\left[\mathrm{Pt}(\mathrm{qS})_{2}\right]^{2-}$ modes is given in ESI

${ }^{a}$ excitation $\lambda=633.8 \mathrm{~nm}$

${ }^{\mathrm{b}}$ doublet: the band $1385 \mathrm{~cm}^{-1}$ is more intense for excitation $457 \mathrm{~nm}$ and the band $1374 \mathrm{~cm}^{-1}$ for excitation $514.5 \mathrm{~nm}$ 
effect of EMV coupling of the $v_{3}\left(\mathrm{a}_{\mathrm{g}}\right)$ mode is seen as an antiresonance dip at $1597 \mathrm{~cm}^{-1}$, similarly as in other TMTTF salts. ${ }^{54}$, 57 This dip is not useful for precise determination of the charge density on TMTTF because due to EMV coupling its position does not exhibit linear dependence on charge. Moreover, in the case of (TMTTF $)_{3}\left[\mathrm{Pt}(\mathrm{qS})_{2}\right]$, the dip can be distorted by the neighbouring band at $1584 \mathrm{~cm}^{-1}$ assigned to the dianion. Three weak bands at 1584, 1576 and $1551 \mathrm{~cm}^{-1}$ are related to the IR active antisymmetric $\mathrm{C}=\mathrm{C}$ stretching $v_{28}\left(\mathrm{~b}_{1 \mathrm{u}}\right)$ mode; these bands correspond to TMTTF molecules with charges $+0.54,+0.64$ and +0.84 , respectively. It is commonly assumed that the $v_{28}\left(\mathrm{~b}_{1 \mathrm{u}}\right)$ mode is the best mode for evaluation of the charge density on TMTTF since it is not coupled with electrons. ${ }^{54}$ However, for most of TMTTF salts, its observation is rather difficult because of polarization along long molecular axis which is usually nearly perpendicular to the best developed crystal face. Nevertheless, the specific arrangement of TMTTF molecules in $(\mathrm{TMTTF})_{3}\left[\mathrm{Pt}(\mathrm{qS})_{2}\right]$ against the crystal face (010) allows detection of the $v_{28}\left(b_{1 u}\right)$ peaks not only for $E \| c$ but also for $E \perp c$, though their intensities are weak (Figure 11 and Figure S6 in ESI). All the vibrational bands observed in IR spectra of the (TMTTF) $)_{3}\left[\operatorname{Pt}(\mathrm{qS})_{2}\right]$ salt together with their proposed assignments are listed in Table 3.

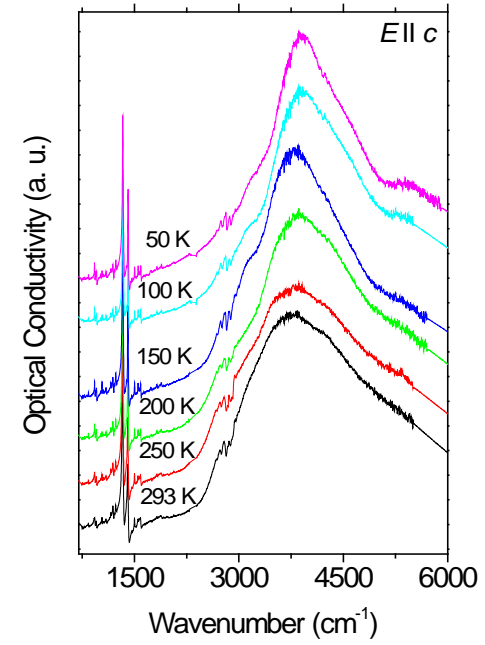

Figure 9. Temperature dependence of the optical conductivity of $(\mathrm{TMTTF})_{3}\left[\mathrm{Pt}(\mathrm{qS})_{2}\right]$ for polarization $E \| c$.

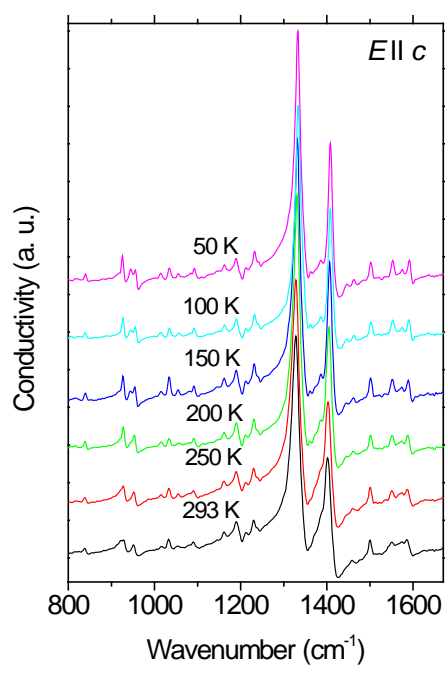

Figure 10. Temperature dependence of the optical conductivity of $(\mathrm{TMTTF})_{3}\left[\mathrm{Pt}(\mathrm{qS})_{2}\right]$ within the region of strong vibrational features (polarization $E \| c$ ).

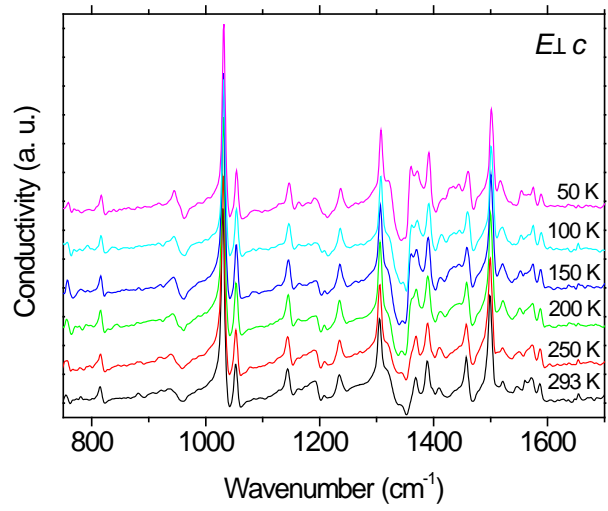

Figure 11. Temperature dependence of optical conductivity of $(\mathrm{TMTTF})_{3}\left[\mathrm{Pt}(\mathrm{qS})_{2}\right]$ within the region of strong vibrational features (polarization $E\lrcorner \mathrm{C}$ ).

On temperature decreasing the intensity of both charge-transfer and vibrational features increases gradually without any indication of phase transition or any visible modification of charge density distribution in TMTTF trimers. The only important change is observed for components of the EMV-activated $v_{8}\left(\mathrm{a}_{\mathrm{g}}\right)$ mode that is the totally symmetric vibration of $\mathrm{CH}_{3}$ groups. ${ }^{53,54}$ As seen in Figure 12 , at ambient temperature, one can distinguish a doublet structure related to the $v_{8}\left(\mathrm{a}_{\mathrm{g}}\right)$ mode at 928 and $950 \mathrm{~cm}^{-1}$. On closer examination one can also distinguish a band at about $920 \mathrm{~cm}^{-1}$, nevertheless its weak temperature dependence indicates that it is not related with the EMV coupling effect, i.e. it cannot be attributed to the $v_{8}\left(\mathrm{a}_{\mathrm{g}}\right)$ mode. On cooling the higher frequency component splits, so that at $T=50 \mathrm{~K}$ a triplet at 926,945 and $956 \mathrm{~cm}^{-1}$ is observed. The $v_{8}\left(\mathrm{a}_{\mathrm{g}}\right)$ mode is involved - as results from crystal structure data in hydrogen bonding with anions. These hydrogen bonds are surely responsible for the doublet structure at ambient temperature and then, when the crystal contracts by temperature lowering, small changes of these bonds yield the additional splitting. 


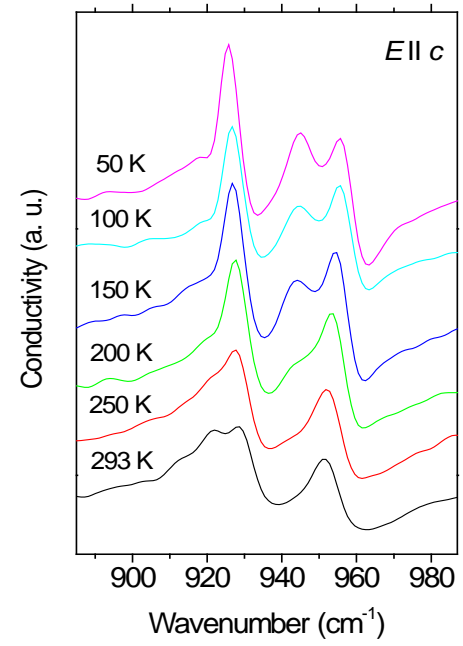

Figure 12. Temperature dependence of the optical conductivity of (TMTTF)3[Pt(qS)2] within the region of $v_{8}\left(a_{g}\right)$ mode (polarization $E \|$ c).

\section{Discussion of IR and Raman spectra}

In general, charge-transfer (CT) salts containing trimers of electron acceptors (or donors) with two unpaired electrons (or holes) are scarce. The most extensively studied was the salt $\mathrm{Cs}_{2}(\mathrm{TCNQ})_{3}$ (where TCNQ is the electron acceptor tetracyano-pquinodimethane). ${ }^{58}$ In this 2:3 salt the TCNQ molecules form strongly trimerized one-dimensional stacks, nevertheless the centrosymmetric trimers cannot be considered as well-isolated. ${ }^{59}$ Similar trimerized TCNQ stacks were also discovered in the salt $\mathrm{MT}_{2}(\mathrm{TCNQ})_{3} \cdot \mathrm{H}_{2} \mathrm{O}$ (where MT is S-methyl thiouronium). ${ }^{60}$ Recently, a new charge-transfer salt ([4-damp $)_{2}\left[\mathrm{Cl}_{4} \mathrm{Q}\right]_{3}$ (4-damp $=$ 4-dimethylamino- $N$-methylpyridinium and $\mathrm{Cl}_{4} \mathrm{Q}=$ tetrachloroquinone) with well-isolated centrosymmetric trimer dianions $\left(\mathrm{Cl}_{4} \mathrm{Q}\right)_{3}{ }^{2-}$ was described. ${ }^{61}$ It is important to note that in these compounds the electron density in trimers is not uniformly distributed among molecules. In $\mathrm{Cs}_{2}(\mathrm{TCNQ})_{3}$ the charges are $-0.14 e$ and $-0.93 e$ on centric and non-centric molecules, respectively. ${ }^{62}$ On the other hand, as estimated by analysis of TCNQ bond lengths, in $\mathrm{MT}_{2}(\mathrm{TCNQ})_{3} \cdot \mathrm{H}_{2} \mathrm{O}$ the charge on the centric $(-0.9)$ is greater than the charge on non-centric $(-0.4)$ molecules. $^{63}$ Similarly, in ([4damp $)_{2}\left[\mathrm{Cl}_{4} \mathrm{Q}\right]_{3}$ the charge in trimers is distributed according to the pattern $-0.59 /-0.76 /-0.59$ (close to the -2 charge imposed by the stoichiometry). ${ }^{61}$ In TTF salts with metal chloride dianions, described by the formula (TTF $)_{14}\left(\mathrm{MCl}_{4}\right)_{4}(\mathrm{M}=\mathrm{Co}, \mathrm{Mn}, \mathrm{Zn})$, two sets of orthogonal TTF trimers with two holes exist in the monoclinic unit cell: two centric trimers are perpendicular to the other two non-centric ones - they alternate in both crystallographic directions (the charge distribution in trimers was not determined in these materials). ${ }^{64}$ There are also two above mentioned 3:1 salts of TMTTF with the dianions $\left[\mathrm{Ti}_{2} \mathrm{~F}_{10}\right]^{2-}$ and $\left[\mathrm{Re}_{2} \mathrm{Cl}_{8}\right]^{2-}$, with doubly charged TMTTF trimers and non-uniform charge distribution. ${ }^{50,51}$

Table 4. Charge distribution in TMTTF trimers at RT as estimated by various methods.

\begin{tabular}{ccc}
\hline \multicolumn{3}{c}{ Charge $(e)$} \\
\hline $\begin{array}{c}X \text {-ray } \\
\text { (Table 2) }\end{array}$ & Raman & $\mathrm{IR}$ \\
& $\mathrm{V}_{10}\left(\mathrm{a}_{\mathrm{g}}\right)$ & $\mathrm{V}_{28}\left(\mathrm{~b}_{1 \mathrm{u}}\right)$ \\
\hline & & \\
+0.5 & +0.45 & +0.54 \\
+1.0 & +0.90 & +0.84 \\
+0.5 & +0.69 & +0.64 \\
\hline
\end{tabular}

The optical properties of trimerized salts were extensively studied both experimentally and theoretically. Though, the first estimation of charge distribution comes from analysis of the bond lengths of donors (or acceptors), more accurate results can be obtained by analysis of the charge sensitive vibrational bands observed in Raman and IR spectra. The analysis of intra-trimer and eventually in some cases also inter-trimer CT excitations allows for evaluation of the electron interactions (Hubbard parameters $U$ and V) and transfer integrals. The vibrational part of IR spectra is dominated by bands activated as a result of EMV-coupling. ${ }^{58}$ The theory of optical properties of a quasi-isolated trimer with uniform charge distribution was developed by Yartsev and applied for IR spectra of $\mathrm{Cs}_{2}(\mathrm{TCNQ})_{3}{ }^{65}$ In the linear approximation, the electrons couple with the totally symmetric $\mathrm{a}_{\mathrm{g}}$ modes of TCNQ molecules. The EMV coupling was described by introducing the internal trimeric modes of vibration. There exist three trimeric modes. Two of the modes are Raman active: the mode corresponding to in-phase vibrations of $\mathrm{a}_{\mathrm{g}}$ modes of three monomers and the mode corresponding to in-phase vibrations of the non-centric molecules together with out-of-phase vibration of the centric molecule. The third trimeric mode is IR active: the non-centric molecules perform out-of-phase $\mathrm{a}_{\mathrm{g}}$ vibrations. Subsequently, to model the influence of counter-ions, Yartsev extended the theory to an arbitrary trimer with non-uniform charge distribution showing that, in this case, the EMV features should exhibit a doublet structure. ${ }^{66}$ On the other hand, Painelli et al. analysed the spectra of $\mathrm{Cs}_{2}(\mathrm{TCNQ})_{3}$ in terms of a model based on vibronic Mulliken theory by considering both intraand inter-trimer CT excitations and assuming that both excitations linearly couple with the totally symmetric $a_{g}$ modes of TCNQ molecule. ${ }^{62}$ An important result of these considerations is that the EMV coupling is responsible for perturbation of the Raman active $a_{g}$ modes (frequency shift). The two CT transitions have also influence on the vibronic IR modes, i.e. the vibronic absorptions are more shifted towards lower frequencies and their intensities are smaller in comparison with the analogous effects expected for one intra-trimer transition only. ${ }^{62}$

The salt $(\mathrm{TMTTF})_{3}\left[\mathrm{Pt}(\mathrm{qS})_{2}\right]$ provides an opportunity for extending the above-mentioned studies for isolated TMTTF trimers with two charges. Our spectroscopic data confirm the results of Xray studies that the charge is not distributed uniformly among molecules in trimers. As seen in Table 4, there exist a small difference between the charge distribution determined from the $v_{10}\left(\mathrm{a}_{\mathrm{g}}\right)$ and $v_{28}\left(\mathrm{~b}_{1 \mathrm{u}}\right)$ modes observed in Raman and IR spectra, respectively. Probably more reliable is $v_{28}\left(\mathrm{~b}_{1 \mathrm{u}}\right)$ since this mode is more sensitive to the charge density. On the other hand, the totally symmetrical $v_{10}\left(\mathrm{a}_{\mathrm{g}}\right)$ mode can be less reliable due to possible influence of the EMV-coupling effect. Generally, the charge distribution in conducting stacks is dependent not only on intratrimer electronic interactions but also on the interactions with the acceptor. The anions exert Coulomb interactions over the cloud of holes in stacks formed by TMTTF molecules. Moreover, as discussed in Introduction, the cloud of holes can be also distorted by the donor-acceptor hydrogen bonding. ${ }^{28,30-32}$ These interactions with $\left[\operatorname{Pt}(\mathrm{qS})_{2}\right]^{2-}$, but first of all the hydrogen bonding, should be directly responsible for the non-uniform charge distribution in trimers.

The TMTTF trimers are well isolated from each other, therefore only intra-trimer CT excitations are important for analysis of 
spectroscopic data. In this case the Raman active $\mathrm{a}_{\mathrm{g}}$ modes are not perturbed by inter-trimer $\mathrm{CT}$ and their positions well correspond to the charge density on molecules. In IR spectra, the $\mathrm{a}_{\mathrm{g}}$ modes are activated by EMV coupling which has to be considered within the model of vibrations of TMTTF trimers (trimeric modes). As emphasized above, only one of the three trimeric modes is IR active (out-of-phase oscillations of non-centric molecules). However, according to the theory of EMV coupling in the trimer with nonuniform charge distribution, ${ }^{66}$ the IR bands should exhibit a doublet (or even triplet) structure. Such doublet structure is only clearly observed for the $v_{8}\left(\mathrm{a}_{\mathrm{g}}\right)$ mode and below about $200 \mathrm{~K}$ the doublet transforms into triplet (Figure 12). A small modification of the hydrogen bonding interactions between donor and acceptor is responsible for this change. It is possible that the strong band related to the $\mathrm{C}=\mathrm{C}$ stretching $v_{4}\left(\mathrm{a}_{\mathrm{g}}\right)$ shows also multiplet structure (Figure 10) but, due to huge deformation by anti-resonance, it is difficult to confirm. This deformation makes also difficult to model this vibronic feature with the trimeric model of EMV coupling.

\section{Conclusions}

Electrocrystallization of TMTTF in the presence of the dianionic $\left[\mathrm{Pt}(\mathrm{qS})_{2}\right]^{2-}$ platinum complex afforded simultaneously two phases. Phase A with isolated dicationic (TMTTF) ${ }_{2}{ }^{2+}$ species is insulating and characterized by $\mathrm{C}-\mathrm{H}$ hydrogen bonds with the anionic sulfonate moieties. Phase B is a mixed valence salt formulated as $(\mathrm{TMTTF})_{3}\left[\mathrm{Pt}(\mathrm{qS})_{2}\right]$, organized into strongly trimerized TMTTF chains, with a notably higher conductivity $\left(\sigma_{R T}=4 \times 10^{-5} \mathrm{~S} \mathrm{~cm}^{-1}\right)$. Charge distribution within the TMTTF trimers was evaluated from the intramolecular bond distances and IR and Raman spectra. The three methods showed a similar charge distribution, described by $+0.5 /+1 /+0.5$ motif, which is not modified at lower temperatures. Small differences between the charges estimated from IR and Raman data can be associated with various charge sensitivity of modes selected for charge evaluation and/or a small contribution of the EMV coupling. While spectroscopic studies of the EMV coupling phenomena in trimers were essentially concentrated on salts of radical anions of TCNQ, the trimeric structure found here in $(\mathrm{TMTTF})_{3}\left[\mathrm{Pt}(\mathrm{qS})_{2}\right]$ provides an opportunity for extending these studies to radical cation salts. In that respect, the doublet (or triplet) structure expected in the IR spectra of such trimers with non-uniform charge distribution is clearly identified in the EMV-activated $v_{8}\left(\mathrm{a}_{\mathrm{g}}\right)$ mode associated with the totally symmetric vibration of methyl groups. The doublet structure is related with weak $\mathrm{C}-\mathrm{H} \cdots \cdot \mathrm{O}$ hydrogen bonds between radical cation and the dianionic $\left[\mathrm{Pt}(\mathrm{qS})_{2}\right]^{2-}$ platinum complex which is responsible for non-uniform charge density distribution inside TMTTF trimer. The transformation of the doublet into triplet structure below about $200 \mathrm{~K}$ gives evidence of small modification of the donor-acceptor hydrogen bonding interactions.

\section{Conflicts of interest}

There are no conflicts to declare.

\section{Notes}

Arkadiusz Frąckowiak https://orcid.org/0000-0002-38352074

Bolesław Barszcz https://orcid.org/0000-0002-3858-1301 Iwona Olejniczak https://orcid.org/0000-0002-7651-7204 Roman Świetlik https://orcid.org/0000-0002-2327-2864 Marc Fourmigué ｈttps://orcid.org/0000-0002-3796-4802
Olivier Jeannin https://orcid.org/0000-0002-1411-5656

Franck Camerel https://orcid.org/0000-0003-3380-709X

\section{References}

${ }^{1}$ U. Geiser, J. A. Schlueter, Chem. Rev., 2004, 104, 5203-5242.

${ }^{2}$ D. Chasseau, D. Watkin, M. J. Rosseinsky, M. Kurmoo, D. R. Talham, P. Day, Synth. Met., 1988, 24, 117-125.

${ }^{3}$ C. Jia, D. Zhang, W. Xu, D. Zhu, Synth. Met., 2004, 140, 9-13.

${ }^{4}$ U. Geiser, J. A. Schlueter, H. H. Wang, A. M. Kini, J. M. Williams,

P. P. Sche, H. I. Zakowicz, M. L. Vanzile, J. D. Dudek, P. G. Nixon,

R. W. Winter, G. L. Gard, J. Ren, M.-H. Whangbo, J. Am. Chem. Soc., 1996, 118, 9996-9997.

${ }^{5}$ H. H. Wang, U. Geiser, J. A. Schlueter, B. H. Ward, J. P. Parakka, A. M. Kini, J. L. O'Malley, S. Y. Thomas, E. Morales, J. D. Dudek,

J. M. Williams, J. M. Gard, Synth. Met., 1999, 102, 1666-1669.

${ }^{6}$ Y. Lakhdar, A. El-Ghayoury, L. Zorina, N. Mercier, M. Allain, C. Mézière, P. Auban-Senzier, P. Batail, M. Giffard, Eur. J. Inorg. Chem., 2010, 2010, 3338-3342.

${ }^{7}$ H. Akutsu, J.-I. Yamada, S. Nakatsuji, S. S. Turner, Crystals, 2012, 2, 182-192.

${ }^{8}$ H. Akutsu, R. Ohnishi, J.-I. Yamada, S.-I. Nakatsuji, S. S. Turner, Inorg. Chem., 2007, 46, 8472-8474.

${ }^{9}$ T. Sugano, T. Fukasaka, M. Kinoshita, Synth. Met., 1991, 41-43, 3281-3284.

${ }^{10}$ E. Fujiwara, S. Aonuma, H. Fujiwara, T. Sugimoto, Y. Misaki, Chem. Lett., 2008, 37, 84-85.

${ }^{11}$ S. Otsubo, H. Cui, H.-J. Lee, H. Fujiwara, K. Takahashi, Y. Okano,

H. Kobayashi, Chem. Lett., 2006, 35, 130-131.

${ }^{12}$ M. M. Matsushita, H. Kawakami, T. Sugawara, M. Ogata, Phys. Rev. B, 2008, 77, 195208.

${ }^{13}$ T. Sugimoto, S. Yamaga, M. Nakai, K. Ohmori, M. Tsujii, H. Nakatsuji, H. Hosoito, Chem. Lett., 1993, 22, 1361-1364.

${ }^{14}$ K. A. Hutchison, G. Srdanov, R. Menon, J.-C. P. Gabriel, B. Knight,

F. Wudl, J. Am. Chem. Soc., 1996, 118, 13081-13082.

15 S. Nakatsuji, H. Anzai, J. Mater. Chem., 1997, 7, 2161-2174.

${ }^{16}$ Y. Nakamura, N. Koga, H. Iwamura, Chem. Lett.,1991, 20, 69-72.

${ }^{17}$ K. Mukai, N. Senba, T. Hatanaka, H. Minakuchi, K. Ohara, M. Taniguchi, Y. Misaki, Y. Hosokoshi, K. Inoue, N. Azuma, Inorg. Chem., 2004, 43, 566-576.

${ }^{18}$ S. Aonuma, H. Casellas, C. Faulmann, B. Garreau de Bonneval, I. Malfant, P. Cassoux, P. G. Lacroix, Y. Hosokoshi, K. Inoue, J. Mater. Chem., 2001, 11, 337-345.

${ }^{19}$ H. Akutsu, J. Yamada, S. Nakatsuji, Chem. Lett., 2003, 32, 1118119.

${ }^{20}$ H. Akutsu, J. Yamada, S. Nakatsuji, Synth. Met., 2005, 152, 377380.

${ }^{21}$ H. Akutsu, K. Masaki, K. Mori, J. Yamada, S. Nakatsuji, Polyhedron, 2005, 24, 2126-2132.

22 A. Yamashita, H. Akutsu, J. Yamada, S. Nakatsuji, Polyhedron, 2005, 24, 2796-2802.

${ }^{23}$ H. Akutsu, J. Yamada, S. Nakatsuji, S. S. Turner, Solid State Commun., 2006, 140, 256-260.

${ }^{24}$ H. Akutsu, S. Yamashita, J. Yamada, S. Nakatsuji, S. S. Turner, Chem. Lett., 2008, 37, 882-883.

${ }^{25}$ H. Akutsu, S. Yamashita, J.-I. Yamada, S.-I. Nakatsuji, Y. Hosakoshi, S. S.Turner, Chem. Mater., 2011, 23, 762-764.

${ }^{26}$ H. Akutsu, K. Sato, S. Yamashita, J. Yamada, S. Nakatsuji, S. S. Turner, J. Mater. Chem., 2008, 18, 3313-3315. 
${ }^{27}$ F. Camerel, G. Le Helloco, T. Guizouarn, O. Jeannin, M. Fourmigué, A. Frąckowiak, I. Olejniczak, R. Świetlik, A. Marino, E. Collet, L. Toupet, P. Auban-Senzier, E. Canadell, Cryst. Growth Design, 2013, 13, 5135-5145.

${ }^{28}$ M. Fourmigué, P. Batail, Chem. Rev., 2004, 104, 5379-5418.

${ }^{29}$ T. Steiner, New J. Chem., 1998, 1998, 1099-1103.

30 J.-P. Pouget, P. Foury-Leylekian, P. Alemany, E Canadell, Phys. Stat. Sol. B, 2012, 249, 937-942.

31 J.-P. Pouget, Crystals, 2012, 2, 466-520.

32 J.-P. Pouget, P. Alemany, E. Canadell, Mater. Horiz., 2018, 5, 590-640.

${ }^{33}$ M. Brezgunova, K. S. Shin, P. Auban-Senzier, O. Jeannin, M. Fourmigué, Chem. Commun., 2010, 46, 3926-3928.

${ }^{34}$ K.-S. Shin, M. Brezgunova, O. Jeannin, T. Roisnel, F. Camerel, P. Auban-Senzier, M. Fourmigué, Cryst. Growth Design, 2011, 11, 5337-5345.

${ }^{35}$ F. Camerel, P. Strauch, M. Antonietti, C. F. J. Faul, Chem. Eur J., 2003, 2003, 3764-3771.

${ }^{36}$ F. Camerel, G. Ulrich, J. Barbera, R. Ziessel, Chem. Eur. J., 2007, 13, 2189-2200.

${ }^{37}$ F. Camerel, J. Barbera, J. Otsuki, T. Tokimoto, Y. Shimazaki, L.Y. Chen, S.-H. Liu, M.-S. Lin, C.-C. Wu, R. Ziessel, Adv. Mater., 2008, 20, 3462-3467.

38 J.-H. Olivier, F. Camerel, J. Barbera, P. Retailleau, R. Ziessel, Chem. Eur. J., 2009, 15, 8163-8174.

39 J.-H. Olivier, F. Camerel, G. Ulrich, J. Barbera, R. Ziessel, Chem. Eur. J., 2010, 24, 7134-7142.

${ }^{40}$ F. Camerel, A. Vacher, O. Jeannin, J. Barberá, M. Fourmigué, Chem. Eur. J., 2015, 21, 19149-19158.

${ }^{41}$ K. Lerstrup, I. Johannsen, M. Jørgensen, Synth. Met., 1988, 27, B9-B13.

${ }^{42}$ A. Altomare, M. C. Burla, M. Camalli, G. Cascarano, C. Giacovazzo, A. Guagliardi, A. G. G. Moliterni, G. Polidori, R. Spagna, J. Appl. Cryst., 1999, 32, 115-119.

${ }^{43}$ G. M. Sheldrick, Acta Crystallogr., 2008, A64, 112-122.

${ }^{44}$ L. J. Farrugia, J. Appl. Cryst., 2012, 45, 849-854.

${ }^{45}$ Gaussian 03, Revision D.01, M. J. Frisch, G. W. Trucks, H. B. Schlegel, G. E. Scuseria, M. A. Robb, J. R. Cheeseman, J. A. Montgomery Jr., T. Vreven, K. N. Kudin, J. C. Burant, J. M. Millam, S. S. Iyengar, J. Tomasi, V. Barone, B. Mennucci, M. Cossi, G. Scalmani, N. Rega, G. A. Petersson, H. Nakatsuji, M. Hada, M. Ehara, K. Toyota, R. Fukuda, J. Hasegawa, M. Ishida, T. Nakajima,Y. Honda, O. Kitao, H. Nakai, M. Klene, X. Li, J. E. Knox, H. P. Hratchian, J. B. Cross, C. Adamo, J. Jaramillo, R. Gomperts, R. E. Stratmann, O. Yazyev, A. J. Austin, R. Cammi, C. Pomelli, J. W. Ochterski, P. Y. Ayala, K. Morokuma, G. A. Voth, P. Salvador, J. J. Dannenberg, V. G. Zakrzewski, S. Dapprich, A. D. Daniels, M. C. Strain, O. Farkas, D. K. Malick, A. D. Rabuck, K. Raghavachari, J. B. Foresman, J. V. Ortiz, Q. Cui, A. G. Baboul, S. Clifford, J. Cioslowski, B. B. Stefanov, G. Liu, A. Liashenko, P. Piskorz, I. Komaromi, R. L. Martin, D. J. Fox, T. Keith, M. A. Al-Laham, C. Y. Peng, A. Nanayakkara, M. Challacombe, P. M. W. Gill, B. Johnson, W. Chen, M. W. Wong, C. Gonzalez, and J. A. Pople, Gaussian, Inc., Wallingford CT, 2004.

${ }^{46}$ R. P. Shibaeva, Kristallografiya (Crystallogr. Rep.), 1984, 29, 480-483.

${ }^{47}$ E. W. Reinheimer, H. Zhao, K. R. Dunbar, Synth. Met., 2008, 158, 447-452.

${ }^{48}$ B. Liautard, S. Peytavin, G. Brun, M. Maurin, Cryst. Struct. Commun., 1982, 11, 1841.

${ }^{49}$ A. S. Batsanov, M. R. Bryce, A. Chesney, J. A. K. Howard, D. E. John, A. J. Moore, C. L. Wood, H. Gershtenman, J. Y. Becker, V. Y. Khodorkovsky, A. Ellern, J. Bernstein, I. F. Perepichka, V. Rotello, M. Gray, A. O. Cuello, J. Mater. Chem., 2001, 11, 21812191.
${ }^{50}$ H. Akutsu, K. Ozeki, T. Ozaki, K. Nozawa, M. Kinoshita, K. Kozawa, T. Uchida, Bull. Chem. Soc. Jpn.,1996, 69, 1869-1873.

${ }^{51}$ E. W. Reinheimer, J. R. Galan-Mascaros, C. J. Gomez-Garcia, H. Zhao, M. Fourmigué, K. R. Dunbar, J. Mol. Struct., 2008, 890, 8189.

${ }^{52}$ P. Guionneau, C. J. Kepert, G. Bravic, D. Chasseau, M. R. Truter, M. Kurmoo, P. Day, Synth. Met., 1997, 86, 1973-1974.

${ }^{53}$ M. Meneghetti, R. Bozio, I. Zanon, C. Pecile, C. Ricotta, M. Zanetti, J. Chem. Phys., 1984, 80, 6210-6224.

${ }^{54}$ M. Dressel, M. Dumm, T. Knoblauch, M. Massino, Crystals, 2012, 2, 528-578.

${ }^{55}$ K. Yamamoto, K. Yakushi, J. Phys IV France, 2004, 114, 153155.

${ }^{56}$ R. Świetlik, B. Barszcz, A. Pustogow, M. Dressel, Phys. Rev. B, 2017, 95, 085205.

${ }^{57}$ A. Pustogov, T. Peterseim, S. Kolatschek, L. Engel, and M. Dressel, Phys. Rev. B, 2016, 94, 195125.

${ }^{58}$ V. M. Yartsev, R. Świetlik, Rev. Sol. State Sci., 1990, 4, 69-117.

${ }^{59}$ C. J. Fritchie, P. Arthur, Acta Crystallogr., 1966, 21, 139-145.

${ }^{60}$ G. G. Abashev, R. M. Vlasova, N. F. Kartenko, A. M. Kuzmin, L. V. Rozhdestvenskaya, V. N. Semkin, O .A. Usov, V. S. Russkikh, Acta Cryst., 1987, C43, 1108-1112.

${ }^{61}$ K. Molčanov, Z. Mou, M. Kertesz, B. Kojić-Prodić, D. Stalke, S. Demeshko, A. Šantić, V. Stilinović, Chem. Eur. J., 2018, 24, 8292-8297.

${ }^{62}$ A. Painelli, C. Pecile, A. Girlando, Mol. Cryst. Liq. Cryst., 1986, 134, 1-19.

${ }^{63}$ V. N. Semkin, S. Y. Priev, R. M. Vlasova, V. M. Yartsev, G. G. Abashev, V .S. Russkikh, Mater. Sci., 1988, 14, 71-76.

${ }^{64}$ Ch. Garrigou-Lagrange, S. Różański, M. Kurmoo, G. Macéno, P. Delhaès. M. Lequan, R. M. Lequan, Sol. Stat. Commun., 1988, 67, 481-485.

${ }^{65}$ V. M. Yartsev, Phys. Stat. Sol. B, 1982, 112, 279-287.

${ }^{66}$ V. M. Yartsev, Synth. Met., 1990, 35, 29-38. 